\title{
Seven Unique Cases of Chondroid Syringomas Reported in KVG Medical College and Hospital
}

\author{
${ }^{1}$ Sudhir M Naik, ${ }^{2}$ Sarika S Naik \\ ${ }^{1}$ Associate Professor, Department of ENT, Head and Neck Surgery, KVG Medical College, Sullia, Karnataka, India \\ ${ }^{2}$ Senior Resident, Department of Anesthesia, KVG Medical College, Sullia, Karnataka, India
}

Correspondence: Sudhir M Naik, Associate Professor, Department of ENT, Head and Neck Surgery, KVG Medical College Sullia-574327, Karnataka, India, Phone: 09916807109, e-mail: sud223@ gmail.com

\section{ABSTRACT}

Chondroid syringoma is a rare, benign, skin appendageal tumor. Because of the unremarkable clinical presentation of this rare tumor, the diagnosis is made on microscopic examination. The usual presentation is of an asymptomatic, slowly growing mass, typically located in the head and neck region.

We present seven cases of chondroid syringomas located over the head and neck region of seven patients in the age group between 32 and 56 years.

In the evaluation of a small cutaneous nodule in the head and neck region, chondroid syringoma should also be considered in the differential diagnosis. For such a lesion, excisional biopsy without destroying the esthetic and functional structures is the preferred diagnostic as well as therapeutic approach.

Keywords: Chondroid syringoma, Excisional biopsy.

\section{INTRODUCTION}

Chondroid syringoma is a rare, benign, skin appendageal tumor. ${ }^{1}$ B ecause of the unremarkable clinical presentation of this rare tumor, the diagnosis is often made after microscopic examination. ${ }^{2}$

W e report seven cases of chondroid syringomas on the forehead and face region (head and neck region).

\section{MATERIALS AND METHODS}

Seven patients presented to the ENT OPD with a progressively increasing swelling on the region of the forehead and other regions in the head and neck. The duration of symptoms ranged from 6 to 18 months. In our study there were one female and six males (Fig. 1). The age group ranged from 32 to 56 years.

The average age among the study group was 44.42 years. The average duration of appearance of tumor was 11.85 months (Table 1).

Physical examination showed a firm, painless, mobile nodule, covered by normal skin. Theaveragesize of thenodule ranged from $3 \times 3 \mathrm{~mm}$ to $9 \times 9 \mathrm{~mm}$ in dimension (Table 1 ). The

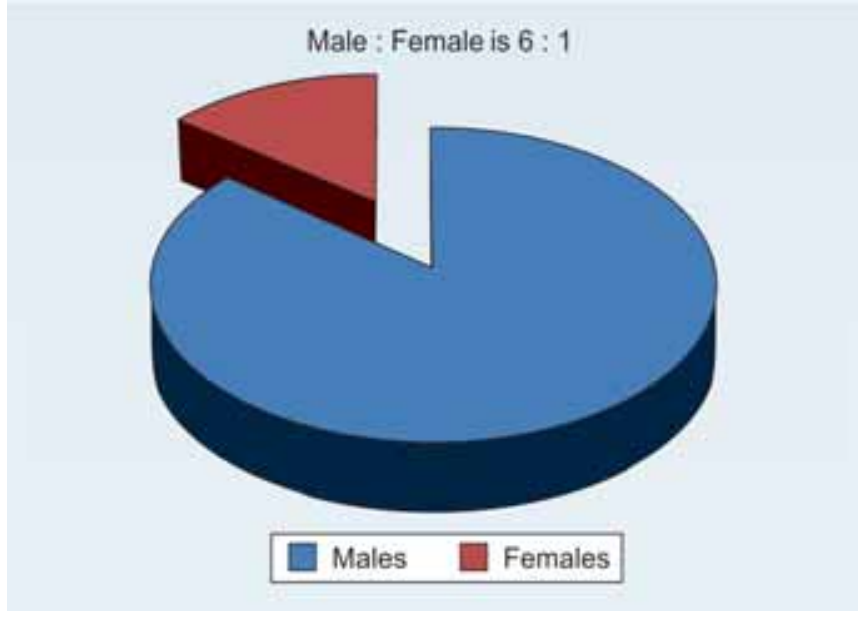

Fig. 1: Higher incidence seen in males in our study

nodules were excised and sent for histopathology. Gross examination showedawell-circumscribed, whitish firm tumor, surrounded with capsule-like tissue.

Histological examination revealed abundant chondroid stroma with fibrous areas containing epithelial and

Table 1: Master chart

\begin{tabular}{cllcl}
\hline Srno. & Age & Sex & Duration of the tumor (months) & Site of the tumor \\
\hline 1 & 32 & M & 10 & Left forehead region $4 \times 4 \mathrm{~mm}$ \\
2 & 44 & M & 12 & Philtrum region $3 \times 3 \mathrm{~mm}$ \\
3 & 46 & M & 6 & Left forehead region $4 \times 4 \mathrm{~mm}$ \\
4 & 51 & $\mathrm{~F}$ & 18 & Left side of dorsum of nose $5 \times 5 \mathrm{~mm}$ \\
5 & 45 & M & Right forehead region $9 \times 9 \mathrm{~mm}$ \\
6 & 56 & M & 15 & Lateral canthus of left eye $6 \times 6 \mathrm{~mm}$ \\
7 & 37 & M & 14 & Right forehead region $4 \times 4 \mathrm{~mm}$ \\
\hline
\end{tabular}


myoepithelial cells, arranged as small aggregates and ducts. The epithelial cells were cuboidal with an eosinophilic cytoplasm and regular oval nuclei (Figs 2 to 5 ).

Based on histopathological findings, a diagnosis of chondroid syringoma was made (Figs $6 \mathrm{~A}$ to $\mathrm{C}$ ). The patients were doing well and there was no recurrence at follow-up.

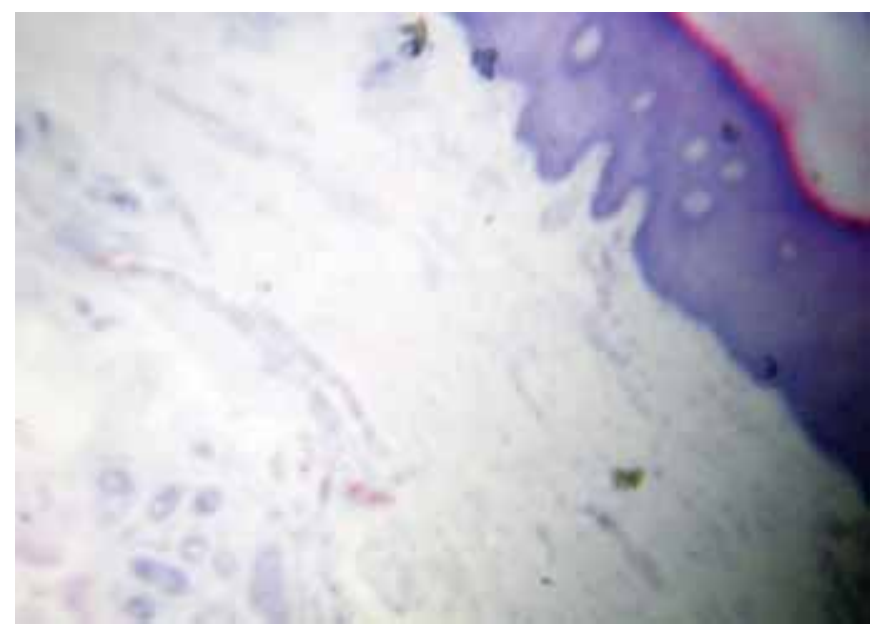

Fig. 2: Chondroid and fibrous stroma in lower magnification
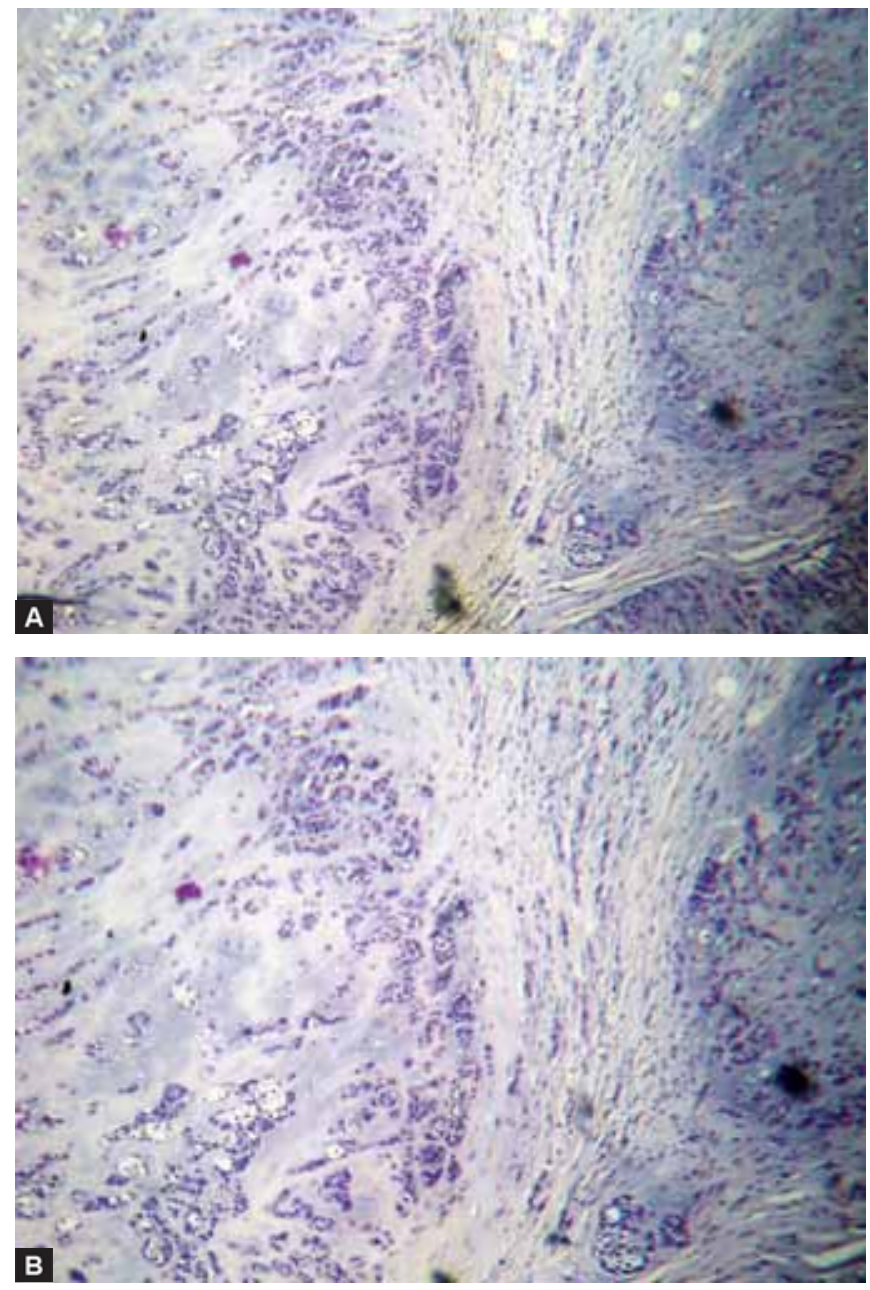

Figs $\mathbf{3 A}$ and $\mathbf{B}$ : Chondroid and fibrous stroma in higher magnification

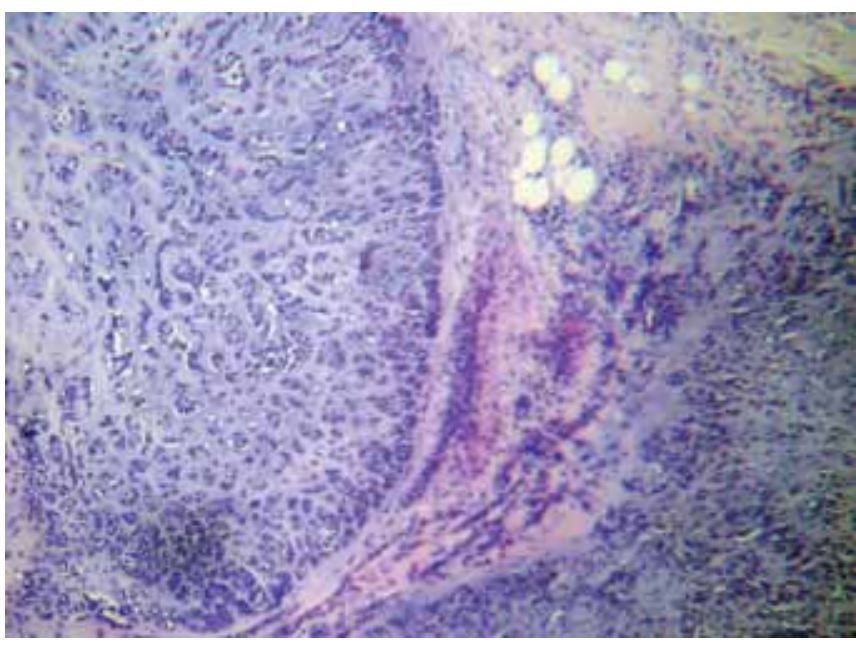

Fig. 4: Epithelial and myoepithelial cells, arranged as small aggregates and ducts

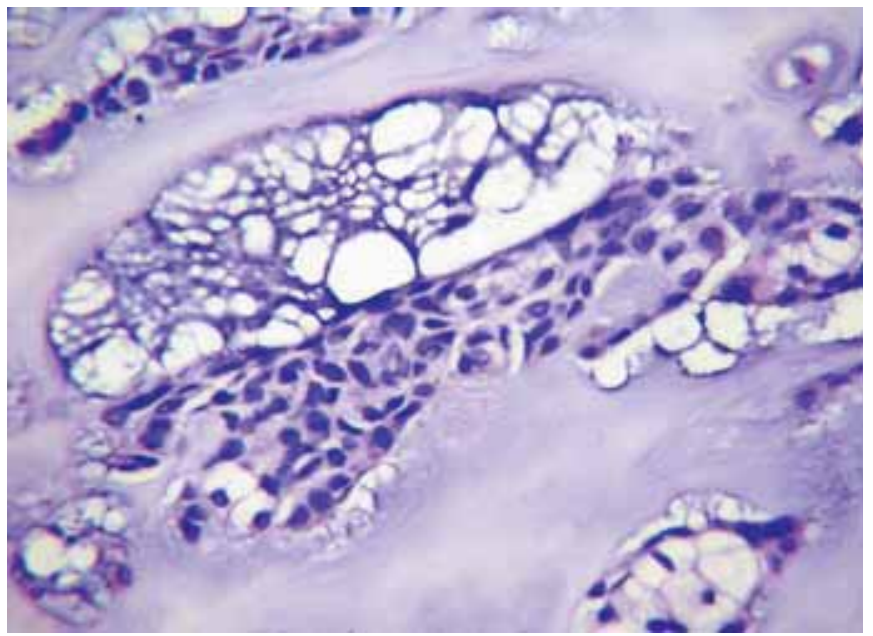

Fig. 5: The epithelial cuboidal cells with an eosinophilic cytoplasm and regular oval nuclei

\section{DISCUSSION}

Chondroid syringoma is rare among primary skin tumors; the reported incidence is $<0.098 \%$. $^{2}$ The tumor usually affects middle-aged or older male patients. ${ }^{2,3}$ The site of predilection for the tumor is the head and neck region; less commonly, these tumors can involve the hand, foot, axillary region, abdomen, penis, vulva and scrotum. ${ }^{2,4-9}$ Typical clinical presentation of these tumors is a slow-growing, painless, firm, nonulcerated cutaneous or intracutaneous nodule $\left(0.5-3 \mathrm{~cm}\right.$ in size) ${ }^{2-4}$

Histologically, chondroid syringoma contains an admixture of epithelial-myoepithelial structures within a chondromyxoid and fibrous stroma arranged in cords and forming tubules. ${ }^{2,11}$ Differentiation toward various skin adnexal structures (including hair matrix, hair follicle, apocrine and sebaceous glands) is rare. ${ }^{12,13}$ The tumor may be confused clinically with various skin lesions, including benign tumors of epidermal or mesenchymatous appendages, such as dermoid or sebaceous cyst and 


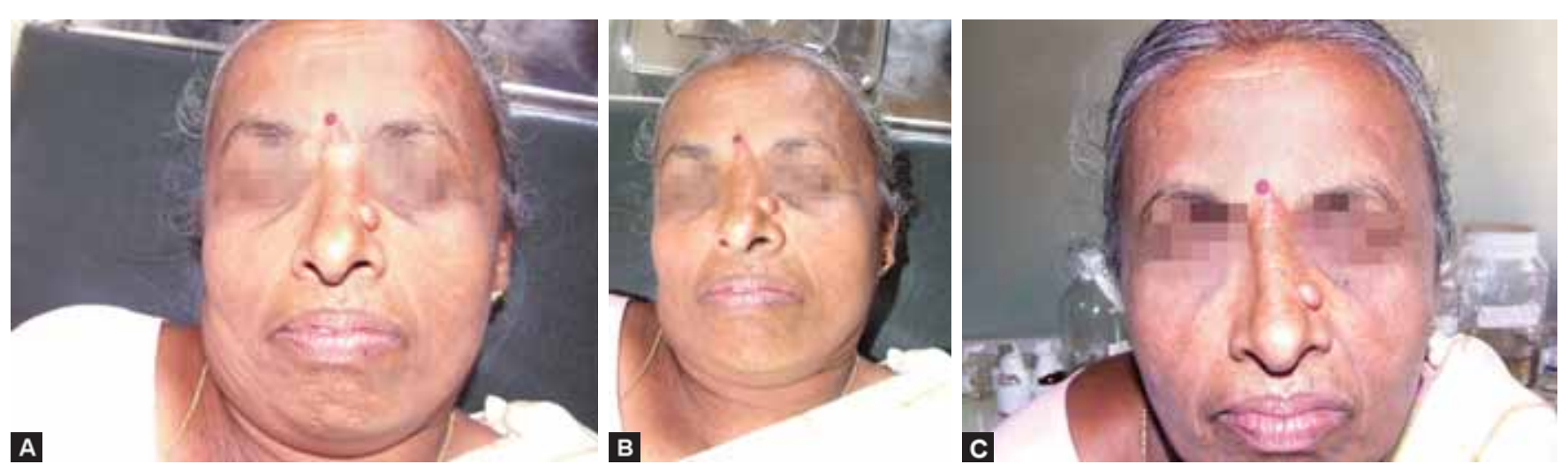

Figs $\mathbf{6 A}$ to $\mathbf{C}$ : Lesion arising from the left lateral side of nose

neurofibroma. ${ }^{2}$ Various treatment options have been proposed for the tumor, including electrodessication, dermabrasion and vaporization with argon or $\mathrm{CO}_{2}$ laser.

B ecause of the risk of malignancy, the first-line treatment is total excision of the tumor without destroying the esthetic and functional structures. This should be followed by regular follow-up to look for local recurrence and any feature of malignancy. ${ }^{14}$

The recurrent lesion can be treated by surgical reexcision. ${ }^{15} \mathrm{M}$ alignant chondroid syringoma is one of the rarest subtypes and appears to behave in an aggressive manner. ${ }^{16,17}$

Malignancy in this tumor is rare, with reported cases occurring in young female patients in the extremities. ${ }^{16,18}$ Tumors greater than $3 \mathrm{~cm}$ in size have a greater likelihood of malignancy. ${ }^{16,19}$

Histological features that suggest malignant transformation in a chondroid syringoma include cytological atypia, satellite tumor nodules, infiltrative margins, tumor necrosis and involvement of deep structures. ${ }^{11,20}$

For malignant lesions, the initial treatment modality is aggressive surgery. A djuvant radiotherapy, with or without chemotherapy, may be recommended. ${ }^{16,17}$

\section{CONCLUSION}

In the evaluation of a middle-aged patient usually male with a small cutaneous nodule in the head and neck region, chondroid syringoma should be considered in the differential diagnosis. For such a lesion, excisional biopsy without destroying esthetic and functional structures is the preferred diagnostic as well as therapeutic approach.

\section{REFERENCES}

1. Zimmerman LE, Sobin LK. Histological typing of tumor of eye and its adnexa. International Histological Classification of Tumor no. 24. Geneva: W orld Health Organisation 1980.

2. $Y$ avuzer R, Basterzi $Y$, Sari A, Bir F, Sezer C. Chondroid syringoma: A diagnosis more frequent than expected. Dermatol Surg 2003;29:179-81.
3. Villalón G, M onteagudo C, M artin J M, et al. Chondroid syringoma: A clinical and histological review of eight cases. Actas Dermosifiliogr 2006;97:573-77.

4. Bekerecioglu M, Tercan M, Karakok M, A tik B. Benign chondroid syringoma: A confusing clinical diagnosis. Eur J Plast Surg 2002;25:316-18.

5. Hardisson D, Linares M D, N istal M. Giant chondroid syringoma of the axilla. J Cutan M ed Surg 1998;3:115-17.

6. Sliwa-Hähnle K, Obers V, Lakhoo M, Saadia R. Chondroid syringoma of the abdominal wall. A case report and review of the literature. S Afr J Surg 1996;34:46-48.

7. Kitazawa T, Hataya $Y, M$ atsuo $K$. Chondroid syringoma of the orbit. A nn Plast Surg 1999;42:100-02.

8. Poku JW, Sant GR, U cci AA. Chondroid syringoma of the scrotum. J Int M ed Res 1996;24:482-86.

9. Nemoto $\mathrm{K}, \mathrm{K}$ ato $\mathrm{N}, \mathrm{A}$ rino $\mathrm{H}$. Chondroid syringoma of the hand. Scand J Plast Reconstr Surg Hand Surg 2002;36:379-81.

10. Hirsch $P$, Helwig EB. Chondroid syringoma. Mixed tumour of the skin, salivary gland type. A rch Dermatol 1961;84:835-47.

11. Bates AW, Baithun SI. A typical mixed tumor of the skin: Histologic, immunohistochemical, and ultrastructural features in three cases and a review of the criteria for malignancy. A $\mathrm{m} \mathrm{J}$ Dermatopathol 1998;20:35-40.

12. Y amamoto $\mathrm{O}, \mathrm{Y}$ asuda $\mathrm{H}$. An immunohistochemical study of the apocrine type of cutaneous mixed tumors with special reference to their follicular and sebaceous differentiation. J Cutan Pathol 1999;26:232-41.

13. Requena L, Sánchez Y us E, Santa Cruz DJ . A pocrine type of cutaneous mixed tumour with follicular and sebaceous differentiation. A m J Dermatopathol 1992;14:186-94.

14. M ebazaa A, Trabelsi S, Denguezli $M$, etal. Chondroid syringoma of the arm: An unusual localization. Dermatol Online J 2006;12:14.

15. Sivamani R, Wadhera A, Craig E. Chondroid syringoma: Case report and review of the literature. D ermatol OnlineJ 2006;12:8.

16. Barnett M D, W al lack M K , Zuretti $A$, et al. Recurrent malignant chondroid syringoma of the foot: A case report and review of the literature. A m J Clin Oncol 2000;23:227-32.

17. Hong JJ, Elmore J F, D rachenberg $\mathrm{Cl}$, J acobs $\mathrm{M}$ C, Salazar OM . Role of radiation therapy in the management of malignant chondroid syringoma. Dermatol Surg 1995;21:781-85.

18. Sungur N, Uysal A, Gümüs M, K oçer U. A n unusal chondroid syringoma. Dermatol Surg 2003;29:977-79.

19. Watson JA, Walker M M, Smith NP, Hunt DM. Malignant chondroid syringoma - a rare cause of secondary bone tumour. Clin Exp Dermatol 1991;16:306-07.

20. B orman H, Özcan G. Chondroid syringoma at the fingertip: A $n$ unusual localization. Eur J Plast Surg 1998;21:311-13. 